The rubmitted manuscript bas been

authorized by a contractior of the U.S.

Government under contract No. DE-ACOS-

960R2464. Accordingty, the U.S. Goverm-

axent retsins a Donescrusive, royalgy-free

licenue to publish or reproduce the published

form of this contribution, or allow others to

do so, for U.S. Government purpowes"

\title{
THE EFFECT OF LOCATION AND FACILITY DEMAND ON THE MARGINAL COST OF DELIVERED WOOD CHIPS FROM ENERGY CROPS: \\ A CASE STUDY OF THE STATE OF TENNESSEE
}

\author{
R.L. Graham, Ph.D.; W. Liu, M.S.; M. Downing, Ph.D. \\ Biofuels Feedstock Development Program \\ Oak Ridge National Laboratory, Oak Ridge, Tennessee 37831-6038, U.S.A \\ C. Noon, Ph.D. and M. Daly, M.S. \\ Management Science Program \\ The University of Tennessee, Knoxville, Tennessee 37966-05628, U.S.A. \\ A. Moore, M.S. \\ Energy Technology Support Unit \\ Dept. of Trade and Industry, Harwell, Didcot OXON 0X11 ORA, U.K.
}

\begin{abstract}
Cost-supply curves for delivered wood chips from short rotation woody crops were calculated for 21 regularly-spaced locations spanning the state of Tennessee. These curves were used to systematically evaluate the combined effects of location and facility demand on wood chip feedstock costs in Tennessee. The cost-supply curves were developed using BRAVO, a GIS-based decision support system which calculates marginal cost of delivering wood chips to a specific location given road network maps and maps of farmgate prices and supplies of woody chips from short rotation energy crops.

Marginal costs of delivered chips varied by both facility location in the state and facility demand. Marginal costs were lowest in central Tennessee unless the facility demand was greater than 2.7 million dry $\mathbf{M g}$ per year ( 3 million dry tons per year) in which case west Tennessee was the lowest cost region. Marginal costs rose rapidly with increasing facility demand in the mountainous eastern portion of the state. Transportation costs accounted for 18 to $29 \%$ of the delivered cost and ranged between $\$ 8$ and $\$ 18 /$ dry $\mathrm{Mg}$ (\$7 and \$16/dry ton). Reducing the expected farmer participation rate from $100 \%$ to $50 \%$ or $25 \%$ dramatically raised the marginal costs of feedstock supply in the east and central regions of the state. The analysis demonstrates the need to use geographically-specific information when projecting the potential costs and supplies of biomass feedstock.
\end{abstract}

${ }^{\prime}$ Research sponsored by the Biofuels Systems Division, U.S. Department of Energy, under contract DE-AC05-960R22464 with Lockheed Martin Energy Research, Corp. 


\section{DISCLAIMER}

This report was prepared as an account of work sponsored by an agency of the United States Government. Neither the United States Government nor any agency thereof, nor any of their employees, makes any warranty, express or implied, or assumes any legal liability or responsibility for the accuracy, completeness, or usefulness of any information, apparatus, product, or process disclosed, or represents that its use would not infringe privately owned rights. Reference herein to any specific commercial product, process, or service by trade name, trademark, manufacturer, or otherwise does not necessarily constitute or imply its endorsement, recommendation, or favoring by the United States Government or any agency thereof. The views and opinions of authors expressed herein do not necessarily state or reflect those of the United States Government or any agency thereof. 


\section{Introduction and Purpose}

The purpose of this study is to systematically quantify both regional differences in the cost of supplying wood chips to biomass energy facilities in the state of Tennessee and the effect of facility demand on those differences. While it is well known that biomass feedstock cost-supply curves will be location-specific, no study has systematically quantified the expected geographic variation in feedstock supply curves for a region. Without some understanding of the geographic variation, it is impossible to assess the magnitude of error of generalizing from one location to another or using aggregate data to make site-specific estimates. This study goes the next step and demonstrates a methodology for quantifying the geographic variation in feedstock supply curves using the state of Tennessee as a case study.

The study extends previous studies by Noon, Graham and Downing in this region (Graham and Downing 1995, Downing and Graham 1995, Graham and Downing 1993, Downing and Graham 1993, Noon et.al. 1993). These studies mapped projected farmgate prices and woody biomass supplies ${ }^{2}$ at a county-level using a breakeven analysis which took into account the density of crop and pasture land, expected yields of woody crops, and current profitability of crop and pasture land ${ }^{3}$. In conjunction with the biomass production estimates, a GIS-based decision support system called BRAVO was developed and applied to assess the probable cost of supplying wood chips from SRWC plantations to specific Tennessee Valley Agency (TVA) power plants in this region. BRAVO uses road networks and farmgate price and supply maps in conjunction with a transportation model to develop delivered cost supply curves for a given location or collection point.

In this study BRAVO is used to develop delivered cost-supply curves for 21 locations evenly spaced across the State. These supply curves are then systematically examined at 10 facility demand levels corresponding to a range of likely power plant or ethanol plant sizes. Regional differences in costs at each demand level are quantified as are (1) portion of the cost attributable to transporting biomass from the farm to the facility, and (2) effect of reducing farmer participation rate (the proportion of the land that is converted to SRWC plantations if the projected farmgate price for wood from that land is met).

2 The term "farmgate price" refers to the wood price needed to induce a farmer to grow SRWC plantations $(\$ / M g)$. In this study the farmgate price is assumed equivalent to the breakeven price - the wood price needed to assure the farmer a profit equal to his current profit. The supply amount associated with a specific farmgate price is the wood that could be grown if all the land of that farmgate price were put into SRWC production.

${ }^{3}$ Profitability of crop land ranged from $\$ 0$ to $\$ 450$ per hectare ( $\$ 0$ to $\$ 182$ per acre) after variable costs (e.g., seeds, fertilizer, farmer labor, custom harvesting), and fixed costs other than land were accounted for. The rental rate of pasture defined the profitability of pasture and ranged from $\$ 36.30$ to $\$ 66.44$ per hectare per year ( $\$ 14.69$ to $\$ 26.89$ per acre per year). SRWC plantations were assumed to yield 5.4 to $9.6 \mathrm{dry} \mathrm{Mg} / \mathrm{ha} / \mathrm{yr}$ (2.4 to $4.3 \mathrm{dry}$ tons/acre/yr) after harvest losses depending on the land type. 


\section{Methods}

\section{Selection of Sites for Supply Curves}

A grid of 21 points evenly spaced across the state was used to define the locations for the BRAVO runs (Figure 1). The collection points were assigned to their respective regions - East, Central, and West. The state of Tennessee falls into three physiographic regions. The eastern third is part of the Appalachian Highlands. It is heavily forested and mountainous with marked parallel ridges and valleys. Agricultural land is limited to valley bottoms and roads tend to parallel the ridges. The central third of the state is part of the Interior plains and is much flatter. The density of agricultural land is higher although forest is still the dominant land cover in many of the counties. The road network is more uniform. The western third of the state is part of the Gulf - Atlantic Plain. Streams flow towards the Mississippi. The agricultural density of the land is higher in this region than the others. As in the central portion of the state, the road network is well developed but the Mississippi River poses a transportation barrier.

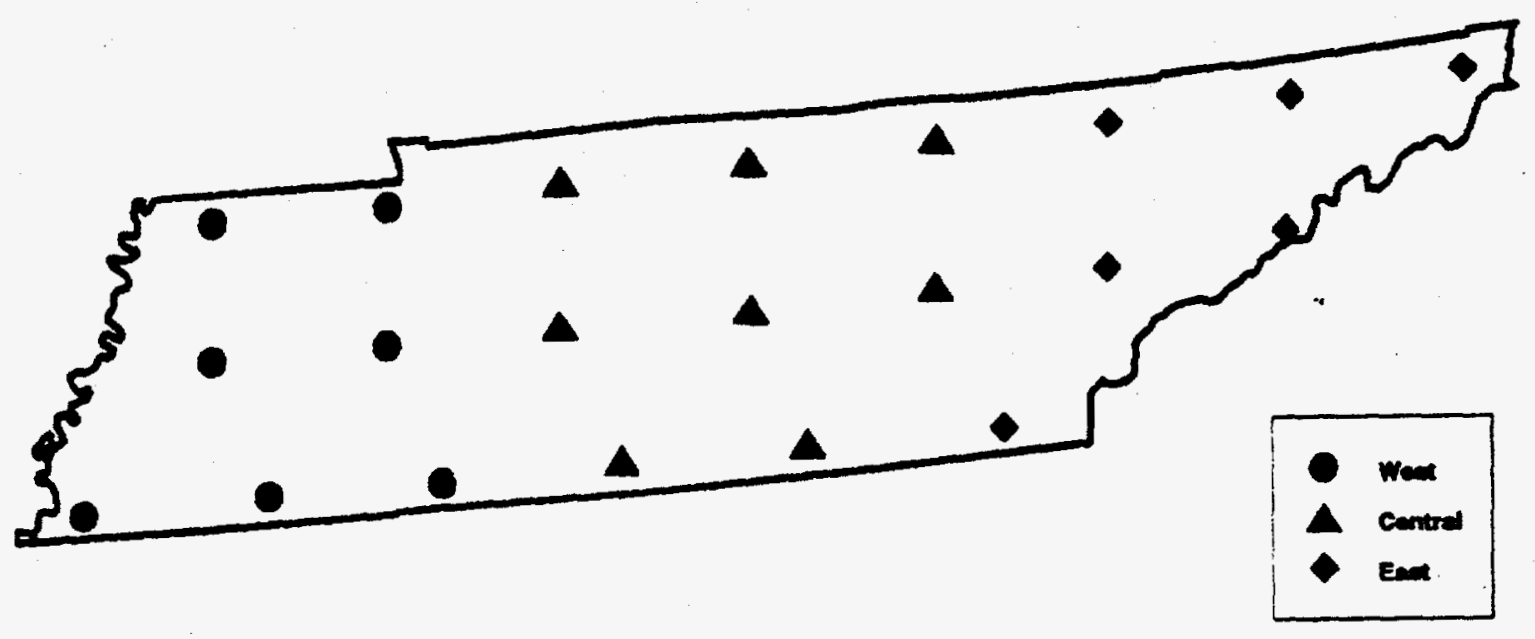

Figure 1. Hypothetical Bioenergy Plant Locations

\section{BRAVO Model Runs}

Previously-developed county-level farmgate price and supply maps for the TVA region (Graham and Downing 1995, Downing and Graham 1995) were used as the biomass maps for the BRAVO runs. The potential wood chip supplies were assumed to be located at the centroid of the county. Each county had 14 potential supplies of wood chips each corresponding to one of the fourteen types of land that could be used to grow SRWC plantations. The amount of each

4 The crop and pasture land in the counties was divided into 14 classes which captured the range of soil suitability for growing conventional crops and/or SRWC. Each class had a unique SRWC yield and farmgate price. 
potential supply was based on the assumption that all the land with that farmgate price was used to grow SRWC plantations (e.g., assumed $100 \%$ farmer participation in SRWC production if the farmgate price was met). BRAVO was run at each collection point to generate a supply curve for that point. Only supplies from counties within $80 \mathrm{~km}$ (50 miles) of the collection point were eligibles. The amount, farmgate price, transport cost and minimum delivered price (sum of the farmgate price and the transport cost) of each supply used in creation of the supply curve was extracted from the BRAVO run and entered into spreadsheets. Supply curves associated with $25 \%$ and $50 \%$ farmer participation rates were generated in the spreadsheet by reducing each individual supply amount (as extracted by BRAVO) by $75 \%$ or $50 \%$.

\section{Cost and Demand Levels}

The marginal costs of supplying the 10 quantities of wood chips listed in Table 1 for $100 \%, 50 \%$ and $25 \%$ farmer participation were extracted from the supply curves in the EXCEL spreadsheets. The mean transportation cost and farmgate price of the supplies needed to achieve a specific demand level were calculated for each location.

Table 1. The demand levels examined in the study.

\begin{tabular}{|l|c|c|}
\hline Type of facility & Size of facility & $\begin{array}{c}\text { Wood demand } \\
(000 \mathrm{Mg} / \mathrm{yr})\end{array}$ \\
\hline Power & $20 \mathrm{MW}$ & $90(100 \mathrm{tons} / \mathrm{yr})$ \\
\hline Power & $50 \mathrm{MW}$ & $230(250 \mathrm{tons} / \mathrm{yr})$ \\
\hline Power & $100 \mathrm{MW}$ & $450(500 \mathrm{tons} / \mathrm{yr})$ \\
\hline Power & $150 \mathrm{MW}$ & $680(750$ tons/yr $)$ \\
\hline Power & $200 \mathrm{MW}$ & $900(1,000 \mathrm{tons} / \mathrm{yr})$ \\
\hline Ethanol & $2,300 \mathrm{Mg} /$ day $(2,500$ tons/day) & $750(825$ tons/yr $)$ \\
\hline Ethanol & $4,500 \mathrm{Mg} /$ day $(5,000$ tons/day) & $1,500(1,650$ tons/yr $)$ \\
\hline Ethanol & $6,800 \mathrm{Mg} /$ day $(7,500$ tons/day $)$ & $2,200(2,475$ tons/yr $)$ \\
\hline Ethanol & $9,000 \mathrm{Mg} /$ day $(10,000$ tons/day $)$ & $3,000(3,300$ tons/yr $)$ \\
\hline Ethanol & $18,000 \mathrm{Mg} /$ day $\left(20,000\right.$ tons/day $\left.{ }^{7}\right)$ & $6,000(6,600$ tons/yr $)$ \\
\hline
\end{tabular}

${ }^{5}$ Counties outside of Tennessee but within $80 \mathrm{~km}$ ( 50 miles) were included in the runs. To be included only some portion of the county needed to be within $80 \mathrm{~km}$.

${ }^{6}$ Halving participation or doubling demand will have the same effect on marginal cost of the supply. But as participation and demand are different concepts, it is useful to separate them. 
Once the marginal costs for a specific demand level were extracted from the curves for the 21 locations they were grouped by their region - east, central, west as were the mean transportation costs and farmgate prices. The regional means of those variables ( 6 to 8 locations per region) were calculated as were the standard error about those means. Plots showing the mean regional marginal costs, transportation costs and farmgate prices by demand were created. Maps were also made showing the marginal cost of chipped wood from SRWC plantations at each location for supplying a $100 \mathrm{MW}$ power plant and a 9,000 dry $\mathrm{Mg} /$ day $(10,000 \mathrm{dry}$ ton/day) ethanol plant.

\section{Results}

\section{Marginal Delivered Costs by Location and Demand}

Figure 2 shows the mean marginal cost of supplying chipped wood in the three regions of Tennessee assuming $100 \%$ farmer participation - a best case. The central region is the least cost region unless very large amounts of woody chips are

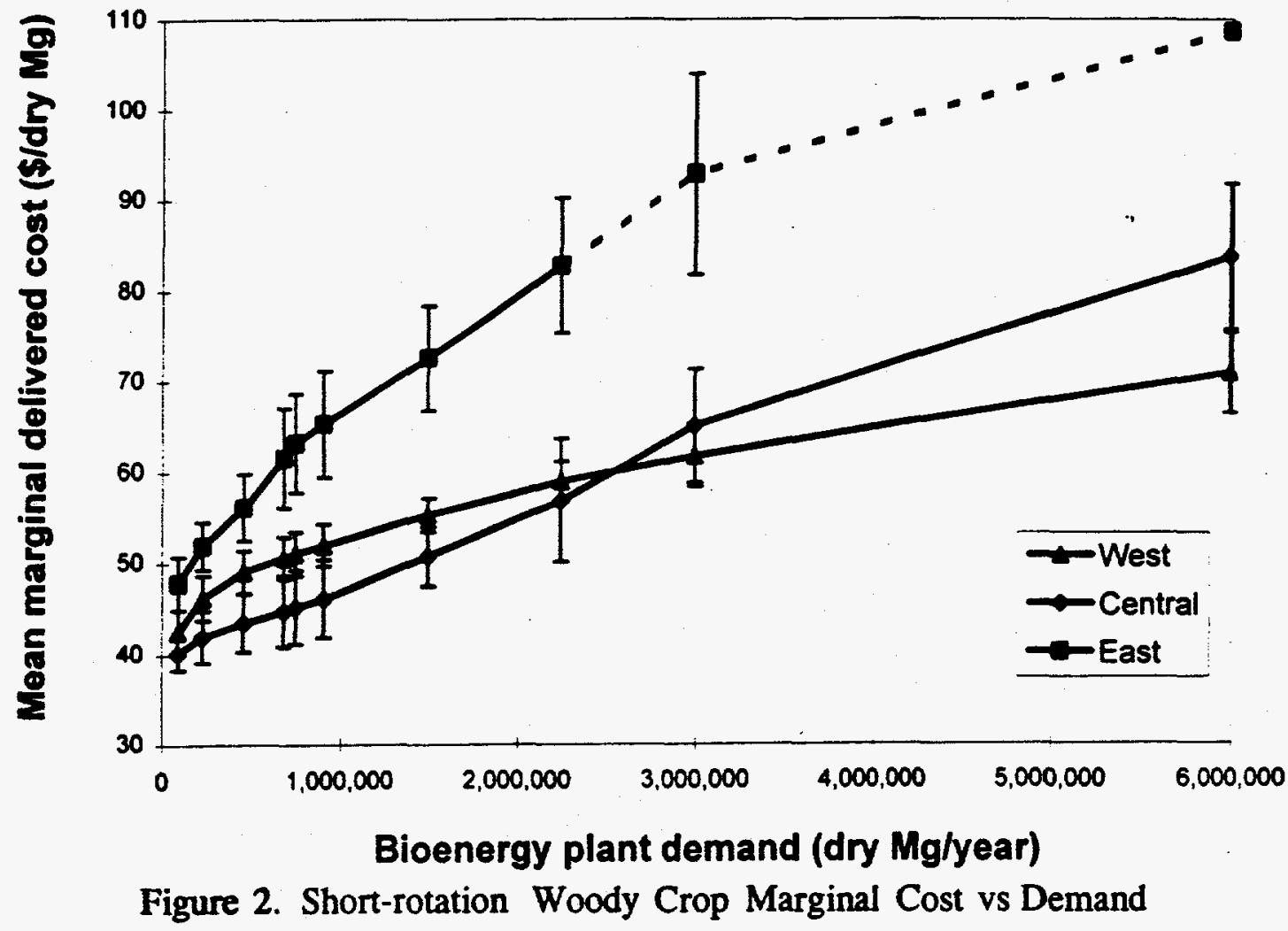

${ }^{7}$ The $18,000 \mathrm{Mg} / \mathrm{day}(20,000$ tons/day) plant is larger than cellulosic ethanol plants are likely to be built. This value was included to show the shape of the curve. Cellulosic ethanol plants may be built that are smaller than $2,300 \mathrm{Mg} /$ day $(2,500$ tons/day) but they are unlikely to be smaller than $450 \mathrm{Mg} /$ day or $300,000 \mathrm{Mg} / \mathrm{year}$ (500 tons/day or 330,000 tons/yr) because of capital costs. 
required (greater than 2.7 million $\mathrm{Mg} / \mathrm{yr}$ ). The eastern region is the highest cost region. Examination of the standard error reveals that the western region is the most homogeneous region; biomass supplies will cost about the same any place within this region regardless of demand. The eastern region shows considerable site to site variation in costs and this variation increases as demand increases. The central region appears intermediate in all regards. Figures 3 and 4 illustrate the point to point variability in feedstock costs at two demand levels.

\section{Production versus Transportation Costs}

Mean transportation and farmgate costs varied noticeably among the three regions (Figures 5 and 6). The central region had the lowest transportation costs and the lowest farmgate costs until very high levels of wood chips were required $(>3$ million dry $\mathrm{Mg} / \mathrm{yr}$ ). Farmgate costs were slightly higher in the western region than in the central region but transportation costs were markedly higher. The higher transportation costs in the west region can be attributed to the transportation barrier presented by the Mississippi River. The east region had the highest transportation costs averaging better than $\$ 15 /$ dry delivered $\mathrm{Mg}(\$ 13 /$ dry ton) even at demands as low as 500,000 dry $\mathrm{Mg}$ per year and assuming $100 \%$ farmer participation. The high transportation costs can be attributed to both the mountainous terrain and the low density of agricultural land. Average farmgate prices were high in the east because the low density of crop and pasture land forced the use of land with high farmgate prices.

\section{Impact of Farmer Participation Rates}

Figures 7 and 8 illustrate the impact that farmer participation has on the marginal cost of supplying woody feedstock in the central and west regions. The impact of farmer participation rate is much greater in the central region than in the west region. Assuming $100 \%$ farmer participation, the west region is the least cost region only for facilities demanding more than 2.7 million dry $\mathrm{Mg} / \mathrm{year}$ (e.g. all but the very largest ethanol plant). Assuming 50\% farmer participation, the west region is the least cost region for facilities demanding more than 1.3 million dry Mg per year (e.g. most ethanol plants) and some of the collection points in each region have an inadequate landbase (within the $80 \mathrm{~km}$ collection radius) for producing 6 million dry $\mathrm{Mg}$ (6.6 million dry tons) of wood a year. At a 25\% participation rate, the western region is the least cost region for any plant requiring more than 750 million $\mathrm{Mg}$ per year (e.g. large power plants and all ethanol plants). Furthermore none of the collection sites in either region could support a 18,000 dry $\mathrm{Mg}$ per day ethanol plant without taking wood from counties farther than $80 \mathrm{~km}$ (50 miles) away and some sites in the central region could not support a 6,800 dry $\mathrm{Mg}$ day (7,500 dry ton day) ethanol plant. The within-region variability in delivered costs at a given demand level increases in the central region but not the western region as the farmer participation rate decreases. Thus from

8 The east region shows the same trends as the central region but more dramatically. Most of the east sites cannot supply more than 2 million dry $\mathrm{Mg}$ regardless of delivered price because the total agricultural landbase is inadequate. 


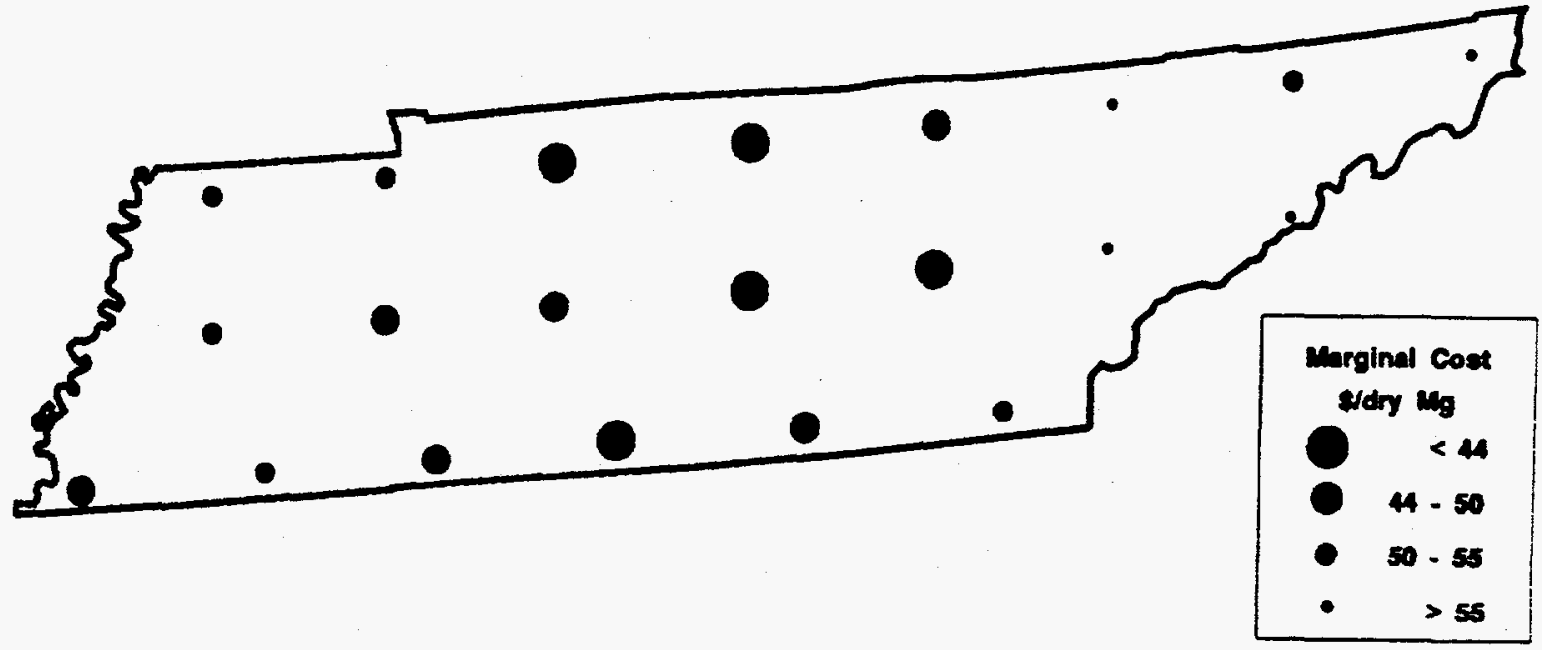

Figure 3. Marginal Cost of Delivered Short-rotation Woody Crop Facility demand $=450,000$ dry $\mathrm{Mg} /$ year $(100 \mathrm{MW})$

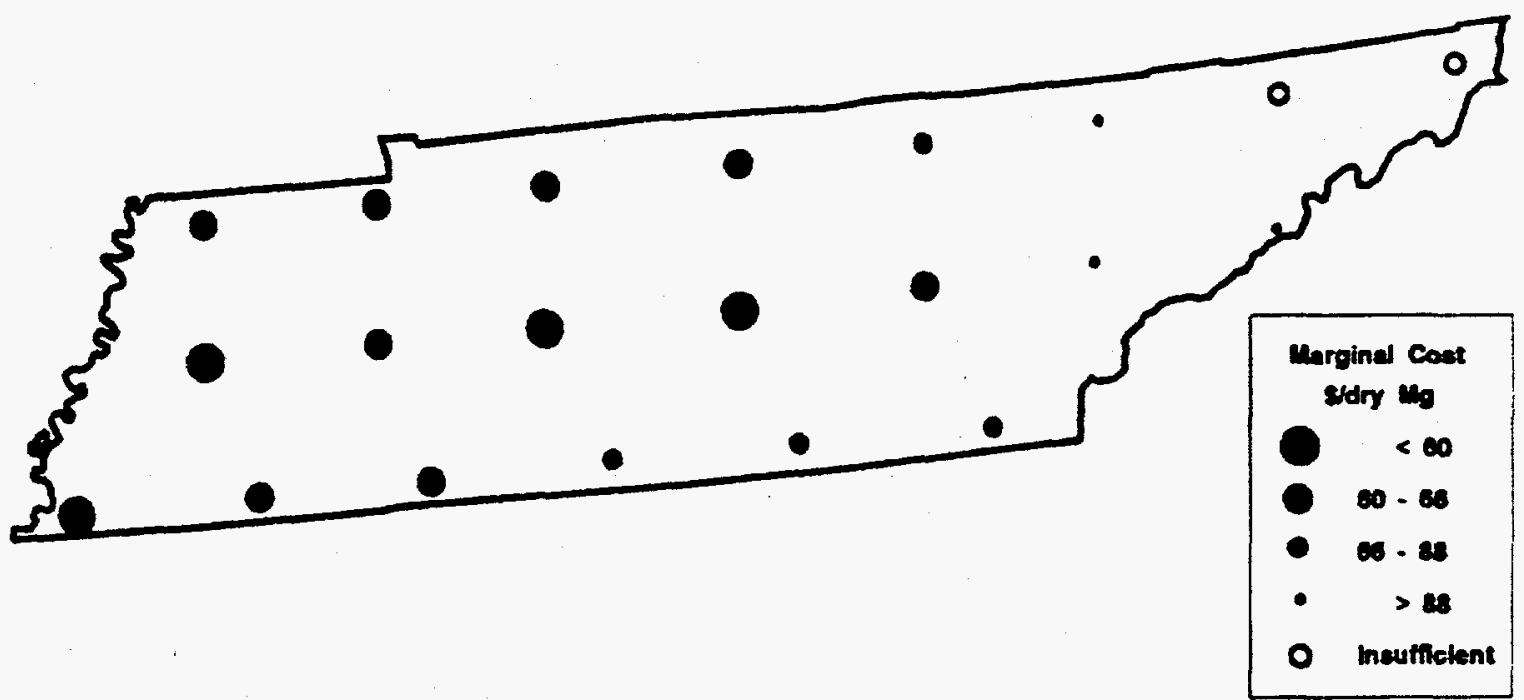

Figure 4. Short-rotation Woody Crop Marginal Cost vs Demand Facility demand $=9,000$ dry $\mathrm{Mg} /$ day (3.13 million liter/day) 


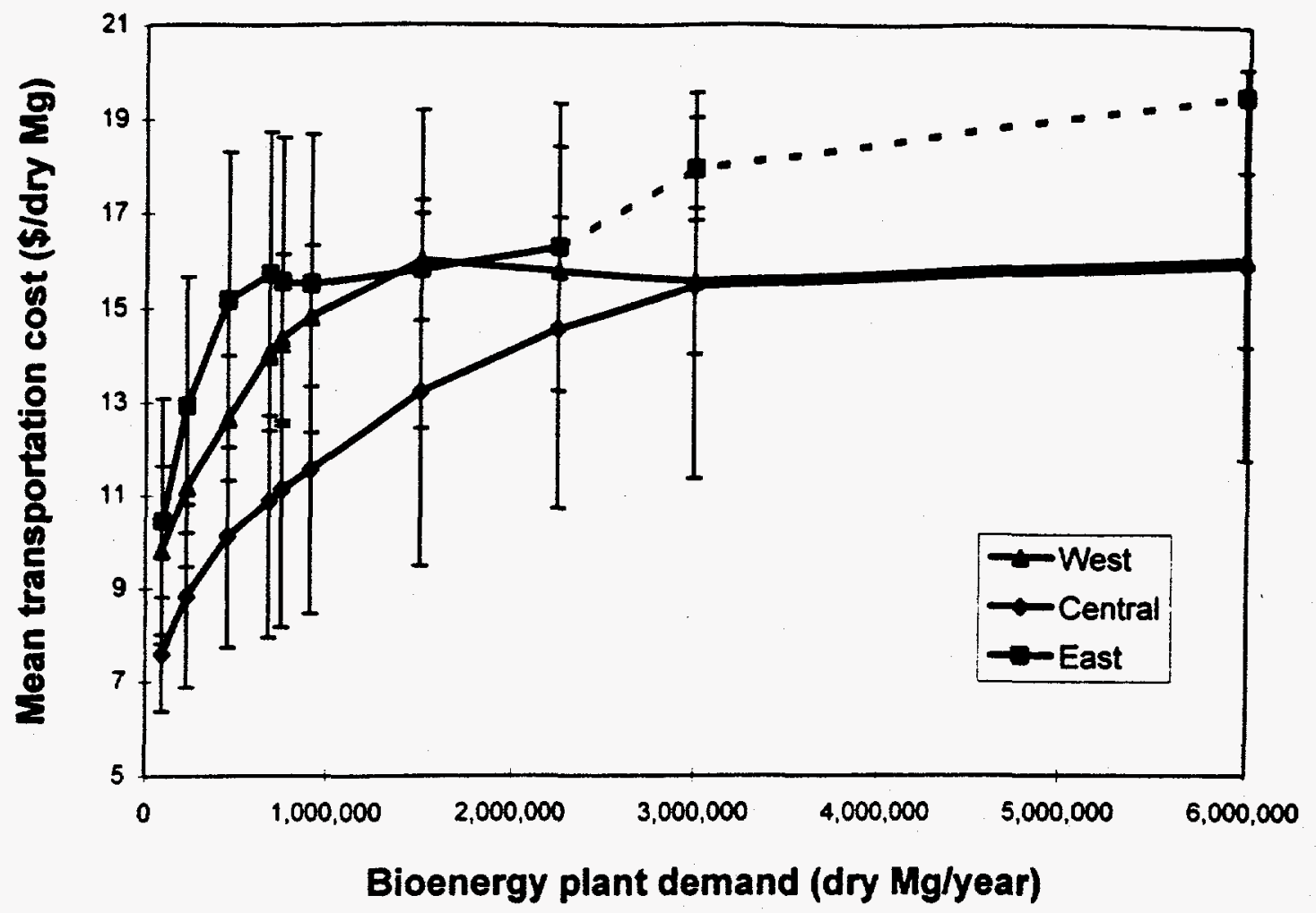

Figure 5. Short-rotation Woody Crop Transportation Costs

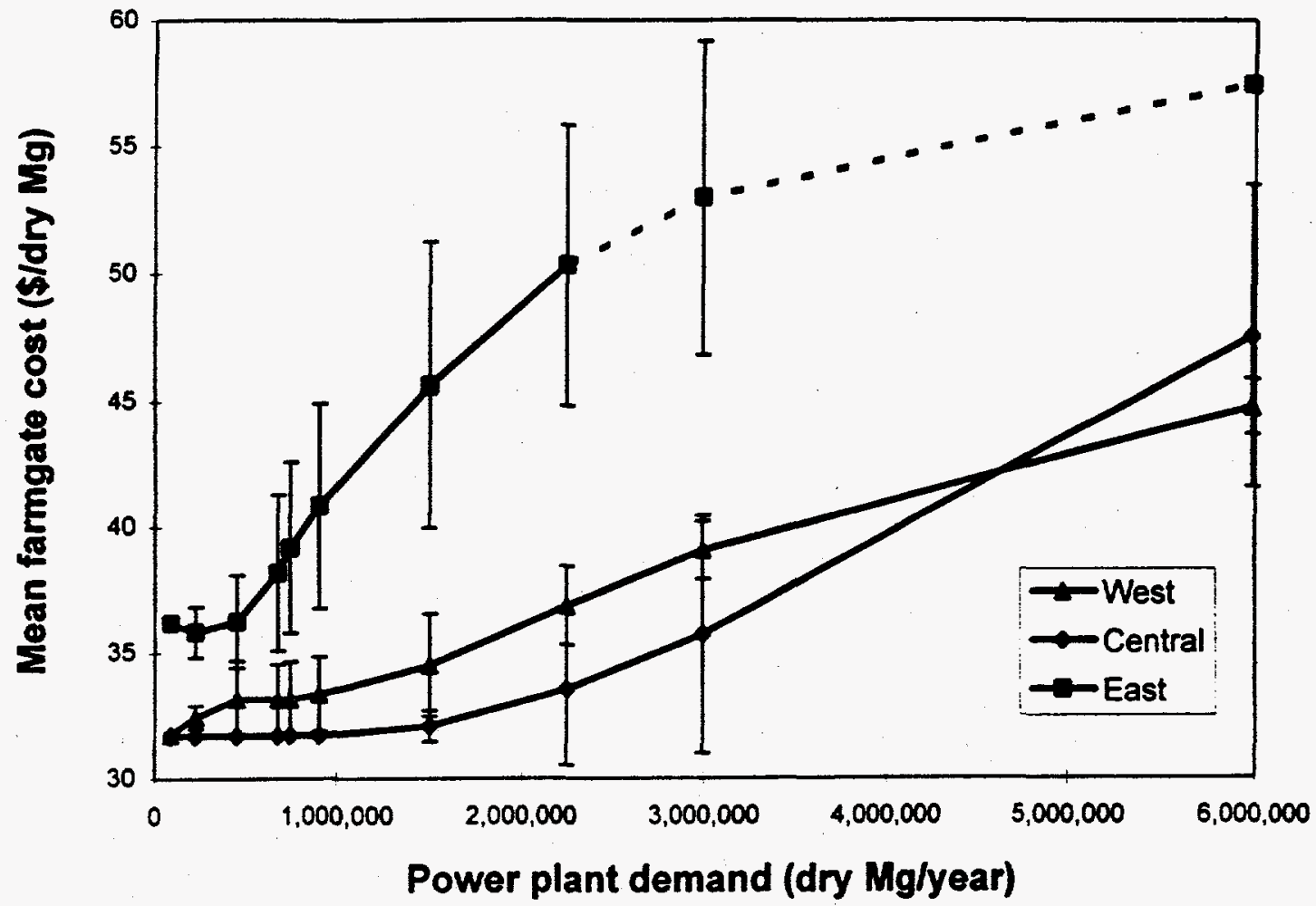

Figure 6. Short-rotation Woody Crop Farmgate Costs 


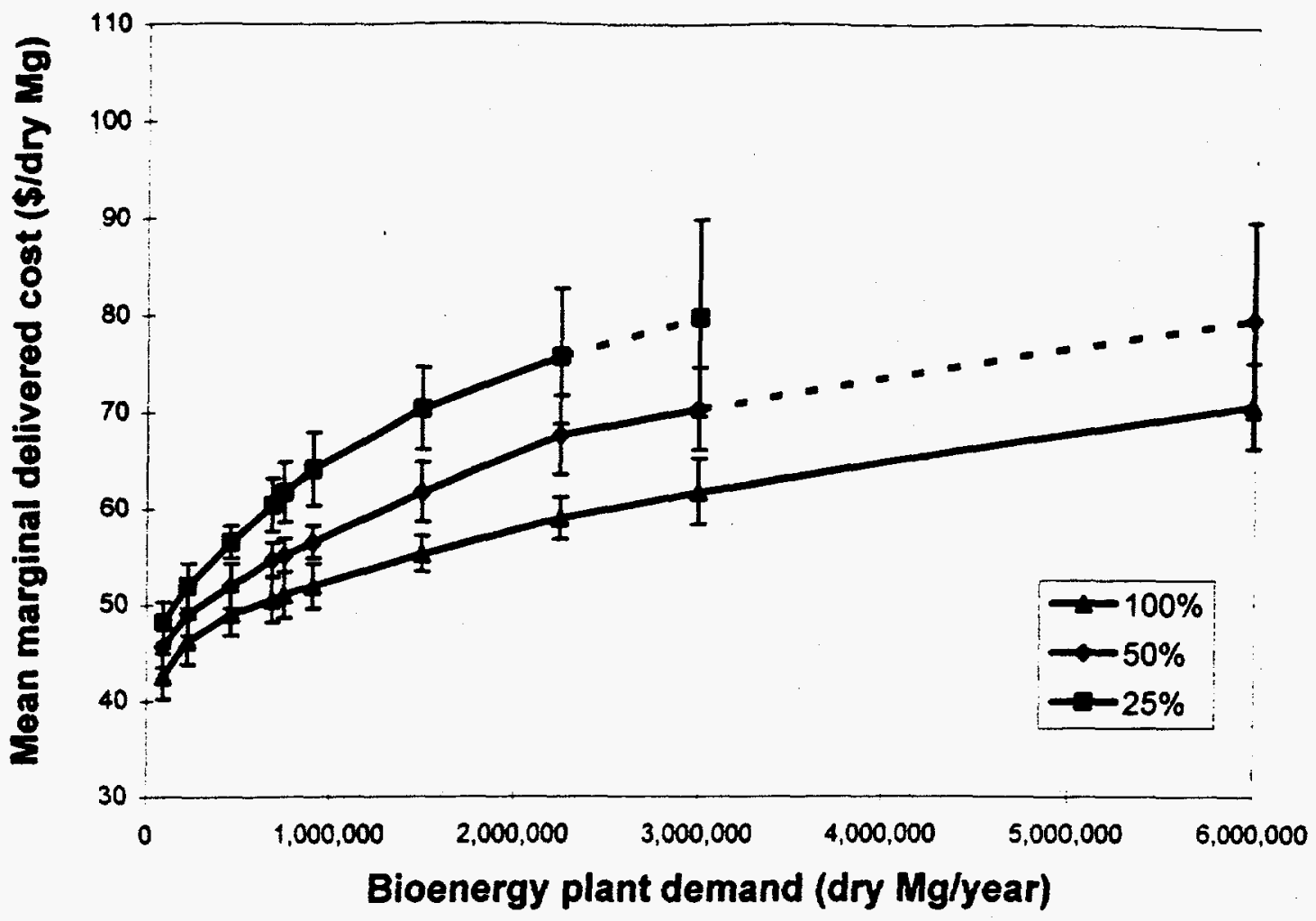

Figure 7. Short-rotation Woody Crop Marginal Cost vs Demand and Farmer Participation Rate - West

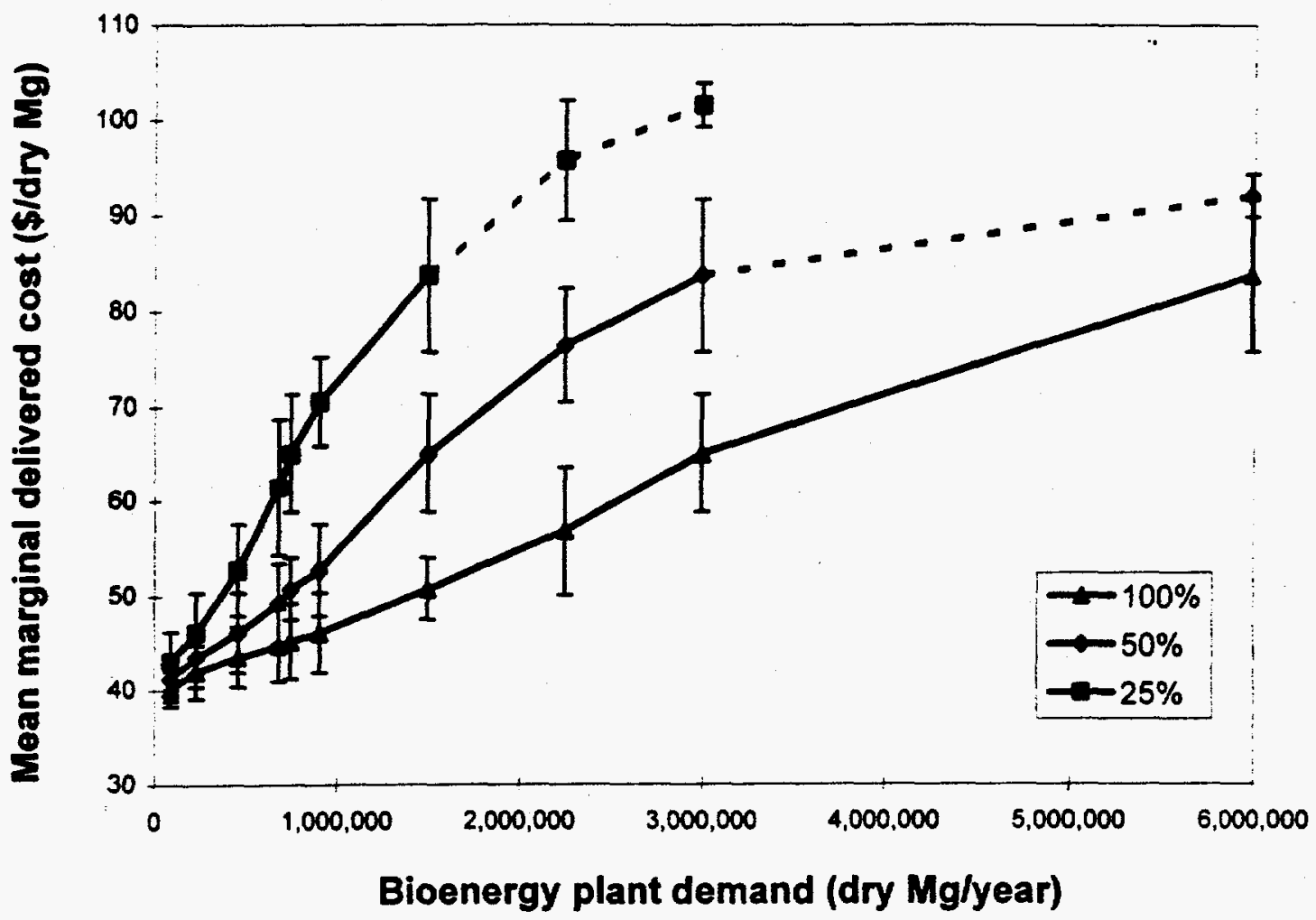

Figure 8. Short-rotation Woody Crop Marginal Cost vs Demand and Farmer Participation Rate - Central 
the perspective of risk reduction, all but the smallest-demand facilities would be better off sited in the western region than in the central region unless they had some mechanism to ensure high farmer participation rates.

\section{Summary}

Biomass facilities will always be faced with dilemma that their feedstock cost will be highly location specific. Using supply curves that are based on aggregate farmgate price information and uniform transportation costs can be misleading. Such curves may obscure opportune locations where biomass supplies can be had inexpensively while at the same time overestimating the total number of facilities that can be supported by feedstock under a specific price. Capturing the geographic complexity of potential biomass supplies is a necessity and one for which GIS is well-suited.

This study demonstrates one approach for quantifying the geographic complexity of biomass supplies and illustrates the need to consider the adoption rate of energy crops by farmers in projecting the likely cost of biomass feedstock.

\section{References}

Downing, M. and R.L. Graham. 1993. Evaluating a biomass resource: the TVA region-wide biomass resource assessment model. Vol I. pp 54-67. In Proceedings of the First Biomass Conference of the Americas. National Renewable Energy Laboratory, Golden CO.

Graham, R.L. and Downing, M. 1993. Renewable biomass energy: understanding regional scale environmental impacts. Vol III. pp 1566-1581. In Proceedings of the First Biomass Conference of the Americas. National Renewable Energy Laboratory, Golden CO.

Noon, C.E. 1993. TVA GIS-based biomass resource assessment. Vol. I. pp 74-78. In Proceedings of the First Biomass Conference of the Americas. National Renewable Energy Laboratory, Golden CO.

Downing, M. and R.L. Graham. 1995. The potential supply and cost of biomass from energy crops in the Tennessee Valley Authority Region. Biomass and Bioenergy. Accepted.

Graham, R.L. and M. Downing. 1995. Potential supply and cost of biomass from energy crops in the TVA region. Report ORNL-6858. Oak Ridge National Laboratory, Oak Ridge, TN. 


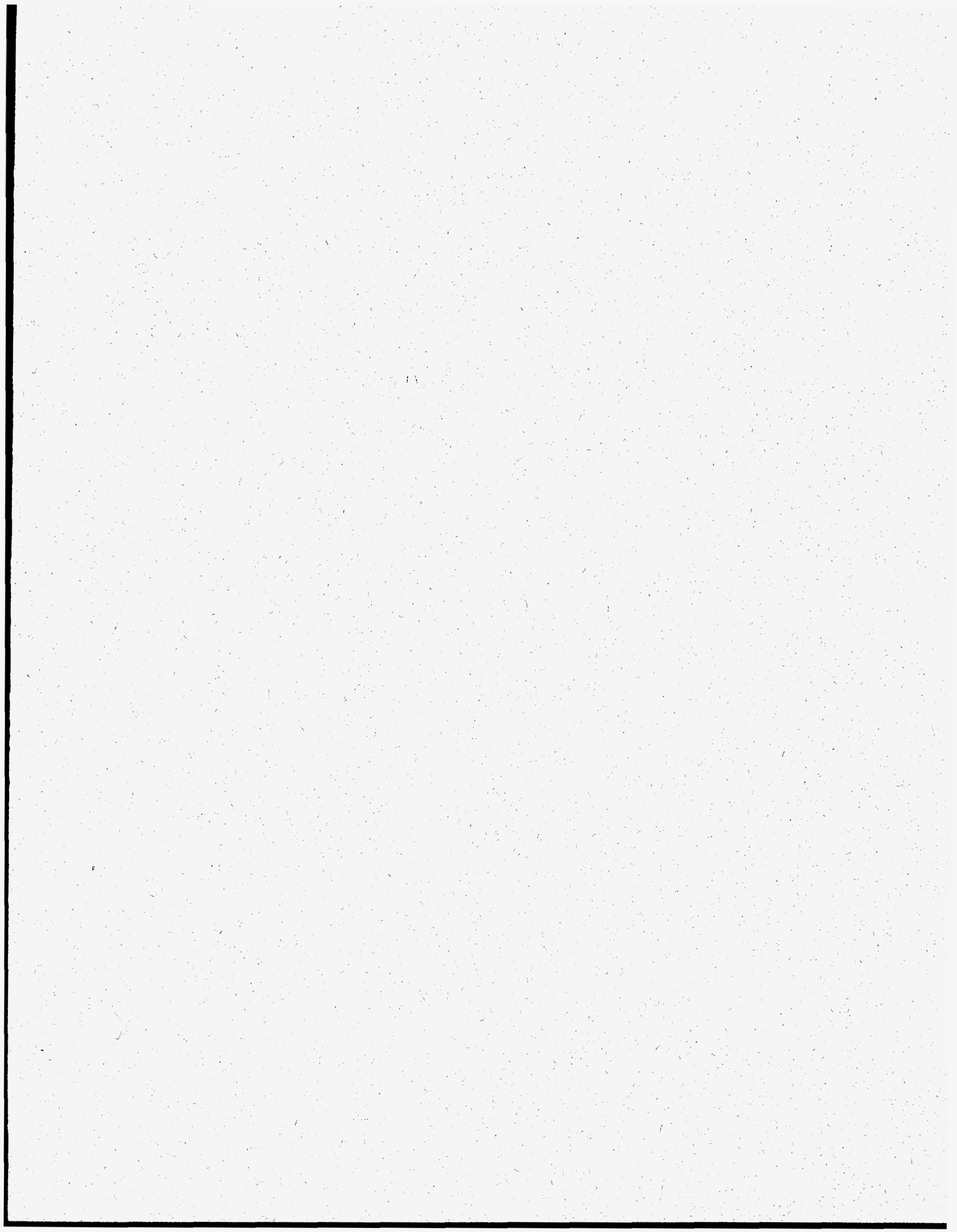

(1) 


\title{
EVALUATING THE ECONOMIC COSTS, BENEFITS AND TRADEOFFS OF DEDICATED BIOMASS ENERGY SYSTEMS: THE IMPORTANCE OF SCALE ${ }^{1}$
}

\author{
R.L. Graham, Ph.D., Ecologist and M. E. Walsh, Ph.D., Agricultural Economist \\ Biofuels Feedstock Development Program \\ Oak Ridge National Laboratory, Oak Ridge, Tennessee 37831-6038, U.S.A
}

\begin{abstract}
The economic and environmental costs, benefits and tradeoffs of bioenergy from dedicated biomass energy systems must be addressed in the context of the scale of interest. At different scales there are different economic and environmental features and processes to consider. The depth of our understanding of the processes and features that influence the potential of energy crops also varies with scale as do the quality and kinds of data that are needed and available. Finally, the appropriate models to use for predicting economic and environmental impacts change with the scale of the questions. This paper explores these issues at three scales - the individual firm, the community, and the nation.
\end{abstract}

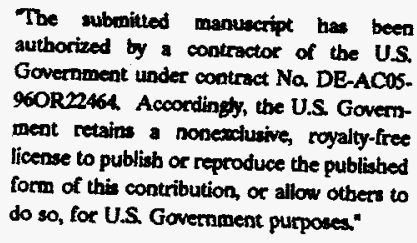

' Research sponsored by the Biofuels Systems Division, U.S. Department of Energy, under contract DE-AC05-960R22464 with Lockheed Martin Energy Research Corporation.

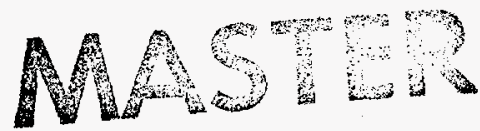


Currently, most dedicated biomass energy sy stems are not economically competitive with their fossil fuel counterparts. Biomass systems that exist have been developed because they are perceived to offer benefits sufficiently valued by society (e.g. improved national security; greenhouse gas mitigation; local economic development; waste reduction) to offset their economic disadvantages. Policy makers considering biomass energy policy must balance the benefits and the costs of these energy systems. To effectively compare different biomass energy systems with each other and with alternative energy systems (e.g., fossil fuel), economic and environmental benefits, costs, and tradeoffs associated with each system must be identified and their social welfare value (worth to society) estimated (Figure 1). Evaluations of this type are difficult. Economists have struggled with placing a market value on goods and services not traded in any market. Environmental scientists have had trouble quantifying environmental impacts. And, to date, no one has satisfactorily found ways to weight the relative costs and benefits of economic and environmental impacts. How does one compare reduction in erosion with improvement in air quality? Or the quantity of jobs with the quality of jobs?

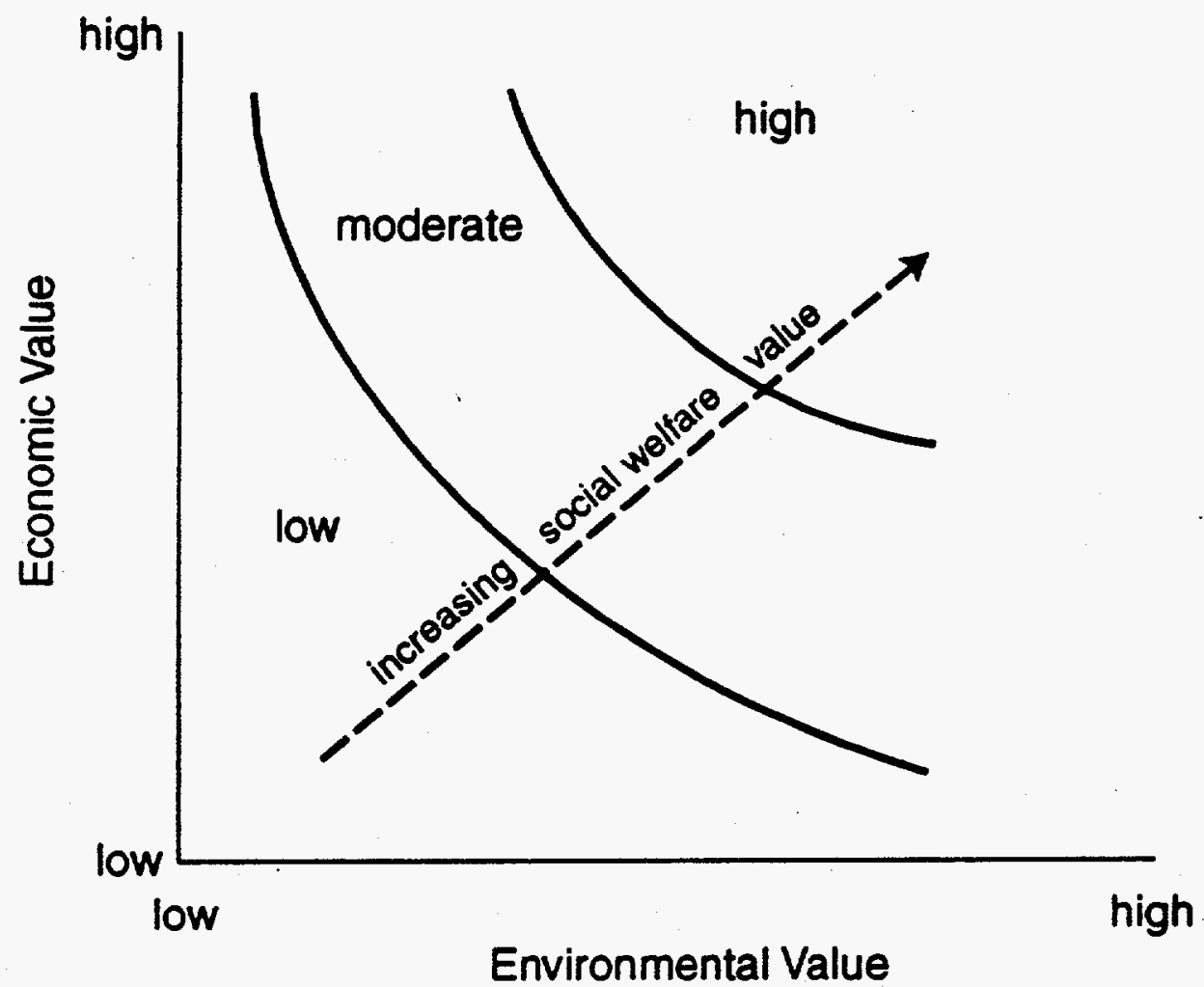

Figure 1. Relating economic and environmental value to social value. 
The social valuation of economic and environmental tradeoffs is complicated by the fact that the values placed on economic and environmental benefits and costs will differ at each scale (aggregation level) of analysis. Thus, social valuation will differ by individual, community, or nation and by firm or industry. Furthermore, our ability to identify and quantify environmental and economic benefits and costs, much less place a relative value on them, also differs by scale. In this paper we take a first step towards developing a model to evaluate the social value of dedicated biomass energy systems by identifying and discussing the relevant scales, and the economic and environmental features associated with each scale. The status of our current ability to quantify environmental and economic impacts is discussed. It is our hope that this characterization will assist in clarifying policy discussions on biomass energy and point the way towards developing models for valuing different biomass energy schemes.

\section{Scales}

The scales relevant to evaluating the economic and environmental tradeoffs associated with dedicated biomass energy systems are (1) the individual firm level (i.e., the farm and the conversion facility); (2) the community level (i.e., the interaction of aggregate farms and a conversion facility with each other and their associated goods and service providers, as well as the firm interactions with and impacts on local infrastructure, institutions, and economic base); and (3) the national level (the interaction of all firms and consumers resulting from the production and use of bioenergy, and the interactions and affects on national institutions). These scales coincide well with the scales at which economic or political decisions ${ }^{2}$ are made and overlap reasonably well with typical environmental scales (e.g., the field site, the watershed or landscape, and the biome).

\section{Individual Firm Scale}

\section{Farm}

The economic and environmental costs, benefits and tradeoffs of dedicated biomass energy systems to the individual farm firm revolve around the replacement of conventional crop production with dedicated energy crop production. The economic features most relevant at this scale are the average relative profitability of biomass crops compared to conventional crops, the variability of expected profits, and how new crops fit into the whole farm management practices.

${ }^{2}$ The state is another scale, at least in the U.S., at which political decisions in particular are made. It is an intermediate scale between the community and the nation and as such contains both community-level and national-level economic and environmental features. The degree to which community-level or national-level economic and environmental features identified in this paper relate to the state scale is dependent on the physical size of the state and it's relative importance to the energy and agriculture sectors of the nation. 
At the firm level, economists typically focus on maximizing profits. To conduct such an analysis, one needs to know the production function and input and output prices for all crops produced. All prices are taken as a given in this approach--the models estimate the level of output that maximizes firm profit. Variations and extensions on the basic approach can be used to estimate supply curves and input demand curves.

Farmers typically have the data (production costs, yields, and prices received, government commodity payments) to compute the historical average profitability and variance of profit for conventional crops, but because biomass crops are new and have not been historically produced, expected profits must be estimated. Average production costs and yield estimates as well as likely selling prices can be used to estimate expected biomass profits. Due to privacy and confidentiality considerations, analysts frequently do not have individual farm data with which to conduct analysis. Given this constraint, economists will typically evaluate "farm" profitability and decision choices by constructing a representative farm based on regional (often county) data regarding the distribution of farms by size, crop and livestock mix, typical management practices, equipment complements, and yields among other factors. Profits to individual farmers will vary, in some cases substantially, from the representative farm estimate.

Evaluation of the expected variability in profits (and hence the risk associated with production) of biomass crops and conventional crops is more complex and involves evaluating the variation in yields, production costs, and selling prices. Additionally, the risk preference of the farmer is significant in understanding the choices a farmer might make when faced with increased risks. Evaluation of production cost and yield variability requires significant knowledge of how climate, soil type, varietal choice, input use, pest outbreaks, crop interactions, and numerous other factors affect production cost and yields. Data and adequate functional forms that quantify and characterize these interactions are frequently lacking. Expected input and product prices may vary substantially in response to local, national, and global events.

Mathematical optimization models, utilizing representative farms, are frequently used to evaluate farm profitability in the whole farm context. These models can be adjusted to include risk factors as well. For example, a model might evaluate maximum profits subject to a constraint of minimum income. Environmental risk constraints can also be included to evaluate how environmental factors might affect profitability.

The environmental features most important to the farm as a firm are loss of land productivity (due to factors such as erosion, increased runoff, or soil carbon losses), pest resistance, weed invasion, groundwater/well contamination, aesthetics (messiness or neatness of fields, integration into the overall landscape), and wetland losses. There is considerable farm to farm variability in the factors affecting these environmental features, so the environmental impacts of biomass crops to individual farms will vary substantially. Unfortunately, quantifying these features is difficult even for a specific farm. Difficulties arise because of needs for farm-specific measurements that are not routine (e g., weediness, soil carbon); lack of models to quantitatively predict changes in the features in response to land management (as in the case of pest resistance, weed invasion, well contamination), and inability to quantify the feature (as in the case of 
aesthetics). Wetland losses and erosion are the most tractable of the environmental features to evaluate for a specific farm as wetland maps exist for many locations and there are accepted models for calculating erosion given crop management practices, weather patterns, and soil. Runoff changes and to some extent leachate can sometimes be modeled with the same information as used for modeling erosion.

Unlike economists, ecologists cannot construct a representative farm to evaluate most "farm" environmental features because there is no information readily available on the distribution of either farm environmental features or the factors controlling those features. Thus characterization of the environmental costs and benefits of bioenergy to the farm firm is limited to environmental analyses of specific farms and there is little ability to generalize to the array of farms found in any region.

\section{Conversion facility}

The economic framework for evaluating the conversion facility is the same as for the farm, since both are individual firms. Data limitations and methodological approaches are analogous. The economic feature of relevance is the profitability of using biomass energy systems compared to alternative energy systems (primarily fossil fuel systems). Similar to farms, individual conversion facility data may be unavailable, but industrywide data and engineering specifications can be used to construct representative conversion facilities. Techno-economic models can be used to estimate the costs of building and operating new facilities using conventional technology, but are not as reliable in predicting the costs of new technologies such as biomass. Biomass risks include uncertainties regarding biomass feedstock price, quantity, quality, and timing of delivery. Biomass feedstock prices will be a function of the quantity demanded by the conversion facility, production costs, yields, profitability of alternative crops, and transportation, storage, and handling costs. Transportation costs will be a function of the density and value of agricultural land surrounding the facility, and the existing road network and local labor costs. Feedstock quality will vary with storage time and moisture content at time of harvesting, among other factors. Additionally, the impacts of biomass energy systems on pollution control activities at a conversion facility must be considered.

The environmental features most relevant to the conversion facility are the facility's air/water emissions and wastes. Data needed to quantify these include the size and technical specification of the bioenergy facility. Facility-specific features (e.g., particulate emissions or tons of ash per MW hour of operation) can be modeled and are independent of facility location. Thus, they are comparatively easy to quantify although the resulting estimates will not be as reliable as with a proven technology. Some impacts important to the facility as a firm (localized erosion, possible loss of animal or plant habitat) may occur in the building of the facility. Although comparatively easy to quantify for a particular facility, these impacts are difficult to generalize as they will be very site dependent.

\section{Community Scale}

At the community scale, the interactions among farms, the conversion facility, support 
industries, and local infrastructure, institutions, and the economic base become more significant in evaluating the economic and environmental costs and benefits of biomass energy systems. It is not sufficient to analyze a firm in isolation to quantify economic and environmental impacts to the community. Unfortunately, formal economic models for community scale analysis are frequently lacking.

From the community perspective, economic features such as the number and quality of jobs produced or lost, impacts on the tax base, and changes in infrastructure (e.g., roads, schools, waste management facilities, water and sewer, etc.) needs and costs become more important in defining the economic value of dedicated biomass energy systems. Size of the conversion facility will be an important factor in determining the quantity of jobs created and demands on infrastructure.

Job creation potential increases with larger facilities as labor needs, farmer participation, input use, and transportation and product distribution needs increase. Direct job creation associated with the conversion facility can be measured relatively easily by determining the number of people needed to build and operate the facility. It is more difficult to measure the number of jobs that may be created in associated supply and support industries--profit maximization models can be used to estimate changes in input demand which will have an indirect multiplier effect on employment levels among input suppliers. Increased employment will have a multiplier effect throughout the community. Estimation of the community multiplier effect is more difficult to estimate--it is often based on changes in per capita income. Additionally, jobs may be lost if a new biomass facility displaces conversion facilities using conventional technologies.

Demands (and thus costs) on local infrastructure facilities might also increase as facility size increases. A complicating factor in estimating the impacts of a biomass conversion facility on the infrastructure needs of a community involves whether or not new people move into the community to take advantage of new economic opportunities. Increased population puts added pressure on infrastructure, at increased cost. Profitability of the plant will affect local taxes that may be collected and potentially influence the quality of the jobs created.

At the community scale, the relevant environmental features for defining the environmental value of dedicated biomass energy systems are stream water quality, plant and animal changes and any local interactions between the conversion facility emissions and construction and the surrounding environs.

Water quality and plant and animal shifts are both related to the landuse change associated with supplying the feedstock to the conversion facility. They are difficult to quantify as they are a function of what farmland changes and where that land is located relative to streams and other land uses. Models exist which will predict stream water quality, and groundwater quality at the community scale ${ }^{3}$ but they require

${ }^{3}$ The community scale coincides spatially with two scales often used in ecological or hydrological literature - the landscape scale and the small to moderate size watershed scale. 
considerable spatially explicit data (topography, soil, weather, land use, land management practices). Furthermore, the data need to be in digital format (i.e., computerized maps). Of these, land-use/land-cover data including where energy crops are likely to be grown are the most problematic data to acquire (or model as in the case of energy crop location). Mapped soils data can also be problematic as they are often not digital. Digital topographic data is generally available but may be of too coarse a quality to use in hydrologic models, particularly for regions with little relief the case of many farming regions. There are no models to directly predict the plant and animal changes that might be associated with the community level production of energy crops. However, habitat-scale models might be able to partially fulfill this need.

Community-level environmental impacts associated with conversion facility emissions and construction and their interaction with community environs will probably not be very significant in most cases as biomass conversion facilities are generally projected to have low air emissions, their wastes are fairly benign, and the facilities are most likely to be constructed at existing industrial sites. However, if the facility is built in an undeveloped area, the visual impact of the facility may be significant to the community as may the potential plant or animal habitat loss. These facility-related effects can be quantified for a specific community but not for communities in general.

In many ways, the necessary environmental data are more available for quantifying environmental features at community level than at the farm level. Generalizing environmental impacts of biomass energy systems to the array of communities where bioenergy facilities might be built is possible (for most of the relevant features) but technically challenging. To construct a general model of the environmental costs and benefits at the community level will require systematically modeling likely land use changes across a large sample of communities that are representative of the distribution of landscapes (e.g. array of soils, land-uses, topography, climate) occurring in the region of interest.

\section{National Scale}

The bioenergy product becomes an important consideration in evaluating the economic and environmental costs, benefits, and tradeoffs at the national scale. At this scale, total demand for the bioenergy product (e.g., electricity or ethanol) will be a deciding factor in determining the number of conversion facilities and quantities of biomass (and hence land base) needed.

The questions of economic interest involving biomass energy systems at the national level are total economic activity generated (gross domestic product); trade balance; job creation (loss); impacts on government expenditures: the cost and economic impact of maintaining national security; and the economic cost and effectiveness of environmental regulation.

Depending on the question to be analyzed and the degree of industry sector interaction 
that occurs, a partial or a general equilibrium approach might be taken. A partial equilibrium approach analyzes one product market and keeps fixed all input and output prices except the price of the product being analyzed. A general equilibrium approach analyzes multiple markets and allows all prices to vary. Large general equilibrium models exist that analyze the impacts of changes in energy prices on employment, government payments, total economic activity, and balance of trade. National security issues can be indirectly addressed by using the models to examine the impact of constraining oil imports. Additionally, agricultural general equilibrium models exist that evaluate changes in farm income, food prices, and balance of trade under a variety of market, technology, and policy conditions. Most of the models allow one to determine employment impacts by sector, and some estimate regional as well as national economic variation, although the regions generally consist of large geographic areas Most of these models do not currently contain a biomass energy sector, however they could be adjusted to do so.

Some of the environmental features relevant at the community-scale related to landuse change are still important at the national scale. These include plant and animal impacts, stream water quality, and wetlands. As at the community scale, our ability to quantify these features varies both in level of effort required and current-level of understanding. Much of the discussion of data needs under community-scale are equally applicable at the national scale. Quantifying plant and animal impacts becomes even more complex at this scale because consideration of bird migration patterns and species extinction becomes important. In addition, water quality modeling may be more difficult because most existing water-quality models appropriate for this scale of analysis are fairly empirical and thus ill-suited for evaluating the impact of a land use for which there is little empirical data.

The new environmental features relevant at this scale relate to the bioenergy product itself and what it replaces. Air quality impacts (e.g., $\mathrm{NO}_{x}, \mathrm{SO}_{x}$, ozone formation, aldehydes, particulates) resulting from the substitution of biomass derived-ethanol or oil for fossil fuel-derived gasoline or diesel, or the substitution of biomass for coal or natural gas for power production are key environmental features at this scale.

Reductions in $\mathrm{CO}_{2}$ emissions resulting from the substitution of bioenergy for fossil energy is another important product-related feature. These product-related features are fairly amenable to quantification, provided a scenario of bioenergy use is assumed (e.g. so many GW of power or liters of ethanol). Publications exist on these subjects and some of the general-equilibrium models could be easily modified to include air quality impacts in their output.

In general, tools exist or could be modified to quantify the economic and environmental tradeoffs of dedicated biomass energy systems (excluding the environmental tradeoffs of land use change). The uncertainty in most of these analyses will reside in their ability to correctly characterize an emerging hybrid (energy-agriculture) industry. 
Firms, communities and nations will face decisions regarding the environmental and economic benefits, costs, and tradeoffs of dedicated bioenergy systems. Our ability to quantify those tradeoffs differs by scale. Environmental benefits, costs and tradeoffs of using bioenergy rather than fossil fuels is probably better understood than anything else. We are just beginning to quantify the environmental benefits, costs, and tradeoffs of growing energy crops rather than conventional crops. The potential economic benefits to the firm (farm or conversion facility) can be readily quantified. Additionally, models exist that with sufficient adjustments could be used to determine national income and employment changes and government expenditures resulting from bioenergy system development. And depending on the model, evaluating employment changes by sector and region is feasible. The community scale is the scale which is most lacking for formal economic models.

\section{DISCLAIMER}

This report was prepared as an account of work sponsored by an agency of the United States Government. Neither the United States Government nor any agency thereof, nor any of their employees, makes any warranty, express or implied, or assumes any legal liability or responsibility for the accuracy, completeness, or usefulness of any information, apparatus, product, or process disclosed, or represents that its use would not infringe privately owned rights. Reference herein to any specific commercial product, process, or service by trade name, trademark, manufacturer, or otherwise does not necessarily constitute or imply its endorsement, recommendation, or favoring by the United States Government or any agency thereof. The views and opinions of authors expressed herein do not necessarily state or reflect those of the United States Government or any agency thereof. 